\title{
Architecture and Properties of PUR/Calcite Composite Scaffolds for Bone Tissue Engineering
}

Ida Dulinska-Molak*, Jakub Jaroszewicz and Krzysztof J Kurzydlowsk

Faculty of Materials Science and Engineering, Warsaw University of Technology, Wołoska 141, 02-507 Warsaw, Poland

\begin{abstract}
Bone tissue has a composite nature given by a highly complex and well-harmonized structure of organic and inorganic components on the microscale, macroscale and nanoscale. Thus, biodegradable composite scaffolds made of poly ( $\varepsilon$-caprolactone) urethane (PCL_PUR) porous matrix and calcium carbonate $\left(\mathrm{CaCO}_{3}\right)$ were developed and studied for bone tissue engineering. The aim of this work was to examine the structure of new polyurethane/calcite composites. Micro-computer tomography $(\mu-C T)$ and image analysis enabled $3 \mathrm{D}$ visualization and quantification of the porosity, wall thickness and internal pore size distribution. The fabricated porous polyurethane composites exhibited porosity $>70 \%$ with a pore size not exceeding $450 \mu \mathrm{m}$ and wall thickness about of $50 \mu \mathrm{m}$ in size. The mechanical properties of the foams were evaluated using Dynamic Mechanical Analysis (DMA). In-vitro bioactivity tests in simulated body fluid (SBF) were carried out and the marker of bioactivity, e.g. formation of surface bone-like apatite layers upon immersion in SBF, was investigated. Our results indicated that PUR/calcite scaffolds were more activity then PUR scaffolds and possessed the function to enhance cell proliferation and differentiation, and might be used as bone tissue engineering materials.
\end{abstract}

Keywords: PUR/calcite composites; Scaffolds; Bioactivity; Porosity; Microtomography

\section{Introduction}

In recent years polymer - bioactive ceramic composite materials have been developed as bone repair devices because of their high bioactivity, biocompatibility and biodegradability. Mainly the first two properties of tissue engineering scaffolds influence the important initial steps related to cell attachment, prior to cell proliferation and differentiation. An important step to engineer tissues is the development of porous three-dimensional scaffolds for different anatomical locations in the body. Ideally, the scaffolds should be porous and the porosity should be both macroscopic for cell growth and migration, as well as microscopic to allow the transport of nutrients and oxygen, as well as the removal of cellular waste products [1]. The relevant properties of ideal scaffolds and the requirements for their successful application in bone tissue engineering have been extensively discussed in the literature [2-6]. They state that scaffolds need to be biocompatible. A three-dimensional (3D) internal geometry, similar to bone morphology, and the retention of mechanical properties after implantation are required for scaffolds in order to maintain a tissue space of prescribed size and shape for tissue formation. Porosity higher than $70 \%$ seems to be necessary. In addition, a macroporosity of 200 $500 \mu \mathrm{m}$ is needed to promote bone cell attachment, and a microporosity should promote ion and liquid diffusion [7].

Among the polymers selected for clinical and surgical applications, polyurethanes (PUR) represent a very important group [8]. Segmented polyurethanes have found application in medicine as biomaterials due to good biocompatibility and good processability [9]. Their domain structure allows one to obtain products with a wide range of physical and mechanical properties. Polyurethanes represent a class of synthetic elastomers, which physicochemical properties may be modified by changing the ratio between soft and hard segments. Therefore, the biodegradable poly ( $\varepsilon$-caprolactone) urethane elastomers are commonly used for production of scaffolds in bone tissue engineering [10-13]. However, the biodegradable polymers in pure form have finite application, connected mainly with their poor mechanical properties and insufficient adhesion of cells that is why their usefulness as implants is limited. The expansion of their application area is connected with preparation of new materials, polymer-ceramic composites, for tissue reconstruction, bringing together advantages of single components: elasticity and strength of polymers with excellent biocompatibility of ceramics, and developing from the type of tissue, they show desired profile of degradation, elasticity or hardness. Composite materials, depending on type of filler used and spatial distribution, introduce large possibilities of designing both mechanical properties and biological behavior of such implant, for example adhesion cells properties. Application of calcium carbonate as a modifying agent allows stimulating the growth of bone tissue [14-17]. These materials, when in contact with the body fluids from on their surface a layer of hydroxyapatite, through with the material used as the implant, forms a permanent bond with the bone in a living organism [18]. Moreover the engineered material composed of PUR and calcite supposes to support a process of creation of a new tissue not only by mechanical properties but as well by biological response. Based on our previous results [19], in the present study, was used the calcite powder as a filler.

The morphogenesis of bone in porous bioceramics when implanted in heterotopic sites was first reported when implanting coral-derived hydroxyapatite specimens in the rectus abdominal muscle of adult non-human primates.

A number of methods have been developed to fabricate polymer scaffolds [1]. One of the most common techniques for producing

*Corresponding author: Ida Dulinska-Molak, Faculty of Materials Science and Engineering, Warsaw University of Technology, Wołoska 141, 02-507 Warsaw, Poland Tel: 48-22-6623158; E-mail: ida.dulinska@gmail.com, idad@meil.pw.edu.p

Received February 26, 2014; Accepted April 11, 2014; Published April 17, 2014

Citation: Dulinska-Molak I, Jaroszewicz J, Kurzydlowski KJ (2014) Architecture and Properties of PUR/Calcite Composite Scaffolds for Bone Tissue Engineering J Bioprocess Biotech 4: 153 doi: 10.4172/2155-9821.1000153

Copyright: (c) 2014 Dulinska-Molak I, et al. This is an open-access article distributed under the terms of the Creative Commons Attribution License, which permits unrestricted use, distribution, and reproduction in any medium, provided the original author and source are credited. 
porous $3 \mathrm{D}$ scaffolds is the particulate-leaching method, which uses inorganic salt particles, gelatin or ice [20,21]. Generally the particulateleaching technique has been combined with other methods, such as phase separation, emulsion freeze-drying or compression moulding for the formation of spatial shapes of larger volume [22,23]. Thus, the objective of this study was to characterize biodegradable polyurethane/ calcite scaffolds for bone tissue engineering fabricated by a salt leaching/ polymer coagulation method. As a result, microstructural, bioactive properties and mechanical characterization of the new composites PUR/calcite foams was presented.

\section{Materials and Method}

Two types of polymeric based samples were prepared: (1) pure polyurethane and (2) polyurethane/calcite composites. The polyurethanes were synthesized using the following reactants: 4,4'dicyclohexylmethane diisocyanates (HMDI), polycaprolactone diol (PCL diol) with molecular weight $530 \mathrm{Da}$, purchased from Aldrich Chemical Co. (Germany). Polyol was dehydrated during mixing under vacuum conditions for two hours at a $120^{\circ} \mathrm{C}$. Ethylene glycol (EG) (POCH, Gliwice) was dried under a molecular sieve. Details of the synthesis of polyurethane and methods for producing $3 \mathrm{D}$ structures described in $[24,25]$.

The calcite powders were prepared at the Institute of Ceramics and Building Materials (ICiMB, Warsaw, Poland). Microscopic observations of their morphology and chemical composition analyses were performed using the scanning electron microscopy (HITACHI) equipped with energy dispersive spectroscope (EDS). Specimens for SEM characterization were coated with a thin film of gold and observed at an accelerating voltage of $15-20 \mathrm{kV}$. Images of the calcite fillers used for PUR modification are presented in Figure 1.

It can be noted that the calcite particles have shape of regular polyhedral. The size of the calcite particles was estimated by laser diffraction (low-angle laser light scattering - LALLS) using a laser analyzer Mastersizer 2000 (Malvern Instruments).

Microarchitectural parameters of scaffolds were evaluated by micro-computer tomography $(\mu \mathrm{CT})$. This non-destructive technique, extensively used to characterize bone speciments [26], is based on $\mathrm{X}$-ray radiation and started to be used for polymer foams $[27,28]$.

According to [29] an essential requirement for in vivo bone growth on a synthetic material is the formation of a carbonated (bone-like)

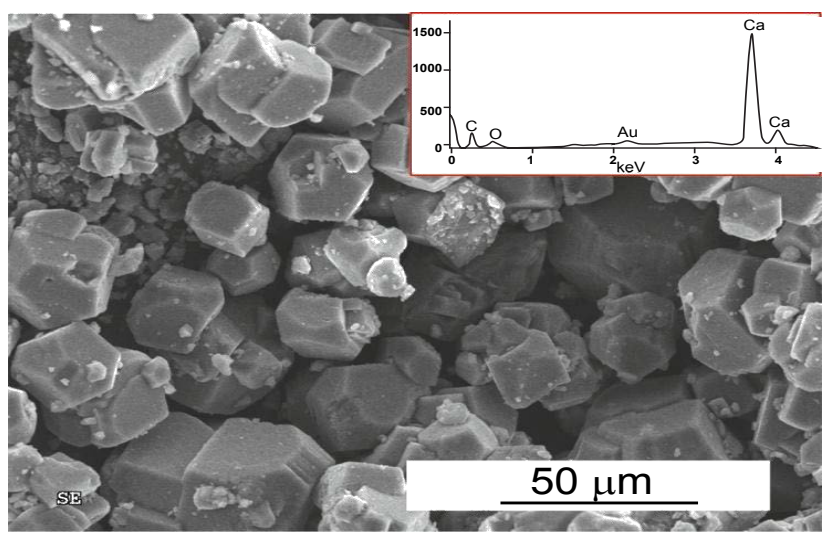

Figure 1: SEM images of the calcite powders used for composite preparation (insets show the corresponding EDS spectra). apatite layer on the material surface. This bone-like apatite seems to act signalizing protein and cells to start the cascade events that result in bone formation. Moreover, the in vivo behavior can be estimated by using in vitro tests like the immersion of synthetic materials into SBF solutions. The bone-like apatite coatings formed on the surface of scaffolds were analysed and compared in terms of morphology, chemistry and structure.

\section{PUR and PUR/calcite composites synthesis}

Segmented polyurethanes with molar ratio of HMDI/PCL/EG 2:1:1 and a constant isocyanate index 1.02 were synthesized in moulds by the pre-polymer method. Soft segments based on a poly(-caprolactone) diol and hard segments were composed of 4,4'-dicyclohexylmethane diisocyanates and EG - the synthesized polyurethanes contain about $52 \mathrm{wt} \%$ of the hard segments (contents of $52 \%$ of hard segments delivers the highest cell viability and proliferation rate). The PCL diol was mixed under vacuum for $2 \mathrm{~h}$ at $120^{\circ} \mathrm{C}$. Next the HMDI was added and the reaction was carried out at a $60^{\circ} \mathrm{C}$ for 3000 seconds. After that, EG was added and the substrates were mixed for 15 minutes. Finally the mixture was kept at a temperature $110^{\circ} \mathrm{C}$ for $16 \mathrm{~h}$ to complete polymerization.

Polyurethane/calcite composites were prepared by in-situ polymerization. Synthesis was performed with a pre-polymer method. PCL diol and calcium carbonate were mixed under vacuum conditions for two hours at a temperature $110^{\circ} \mathrm{C}$. Afterwards, the synthesis proceeded in the same way as for PUR. The fillers were added to the polyurethane matrix in the quantity yielding their weight content equal to $10 \mathrm{wt} . \%$. Poly ( $\varepsilon$-caprolactone) urethane and the composites were synthesized without solvents and catalysts. Before cell research the obtained polyurethane and PUR composite samples were sterilized using ionizing irradiation ( $25 \mathrm{kGy})$. The sterilization method was based on earlier results published in [30].

\section{Polyurethane and PUR/calcite foams preparation}

Porous scaffolds structures were fabricated by the polymer coagulation combined with salt-particle leaching method. The PUR/ calcite composites were ground at liquid nitrogen temperature and dissolved in 1-methyl-2-pyrrolidone at a concentration of $15 \mathrm{wt} . \%$. The $\mathrm{NaCl}$ were fractioned to the size ranging from $300-420 \mu \mathrm{m}$. The particles were subsequently incorporated into the polyurethane solution with mass ratio of polymer to $\mathrm{NaCl}, 1: 5$. The polymer (composite)/salt/ solvent mixture was poured into a teflon mould (6 $\mathrm{mm}$ in diameter) and immersed in distilled water for 2 days, during which time precipitation of the polymer and leaching of the salt particles occurred simultaneously. Water was gently stirred and changed several times in order to increase salt leaching and solvent removal. The obtained porous samples, of thickness approximately $6 \mathrm{~mm}$, were dried under vacuum at $37^{\circ} \mathrm{C}[24]$

\section{Scaffolds morphology}

The surface and cross-section morphologies of the scaffolds and cell-scaffold were examined using a scanning electron microscopy (SEM) (HITACHI) with energy dispersive spectroscopy (EDS). Samples were fixed on a SEM sample holder, air dried under vacuum and coated with a thin layer of gold using an automatic coating sputter which was set at $7 \mathrm{~mA}$ for $3 \mathrm{~min}$ (Polaron SC7640).

\section{Characterization of the scaffolds}

All scaffolds before and after immersion in SBF solution were 
analysed with a X-ray micro-computed tomography ( $\mu \mathrm{CT})$ using a SkyScan 1174 equipment (Belgium). Samples for $\mu \mathrm{CT}$ were mounted on a dedicated sample holder and the tungsten reflection target of the $\mu \mathrm{CT}$ system was set at a voltage of $30-60 \mathrm{kV}$ and a current of $168 \mu \mathrm{A}$. Radiographs with isotropic resolution of $4.9 \mathrm{~mm}$ in terms of pixel/voxel size were acquired by means of a CCD camera of $4000 \times 2096$ pixels binned to $2000 \times 1048$. A frame averaging of 3 and a rotation step of $0.4^{\circ}$ between individual radiographs, covering a view of $180^{\circ}$, were chosen. The projections were processed using a standard cone-beam algorithm and a stack of 2D cross section images of the samples were obtained. The data were analysed with the "CTAn" software package in order to create a 3D representation of the initial microstructure of the foams and to calculate the structural parameters. Quantitative analysis of the porosity and of the pore architectures can be obtained based on VOX/ DT analysis method [31]. The structural parameters reported were the foam porosity (\%), pore diameter and the wall thickness. The porosity was calculated from $100 \times(1-\mathrm{BV} / \mathrm{TV})$, where $\mathrm{BV} / \mathrm{TV}$ is the ratio of the material volume to the total volume, and the average wall thicknesses and pore sizes were taken from the metric index $\mathrm{Tb} . \mathrm{Th}^{\star}$ and $\mathrm{Tb} \cdot \mathrm{Sp}^{\star}$ values. The reported structural parameters corresponded to the average of a minimum of two different samples.

In addition, the porosity of scaffolds was studied by Archimede's method. The porosities were calculated using the following equations:

$$
\begin{aligned}
& \mathrm{V}_{\mathrm{s} 1}=\left[\mathrm{W}_{1}-\left(\mathrm{W}_{2}-\mathrm{Ws}\right)\right] / \rho \\
& \text { Porosity }(\%)=\left(1-\mathrm{V}_{\mathrm{s} 1} / \mathrm{V}_{\mathrm{s} 2}\right) \times 100
\end{aligned}
$$

Where $\mathrm{V}_{\mathrm{s} 1}$ is the volume of the scaffold, $\mathrm{W} 1$ is the weight of the gravity bottle filled with water, $\mathrm{W}_{2}$ is the weight of the gravity bottle filled with water and the immersed scaffold, WS is the weight of the scaffold, $\rho$ is the density of water, $\mathrm{V}_{\mathrm{s} 2}$ is the volume of the entire scaffold. The reported parameters corresponded to the average of a minimum of five different samples.

\section{Dynamic mechanical analysis}

Compression tests by dynamic mechanical analysis (DMA) were carried out on cube shaped specimens with dimensions of $4 \times 4 \times 4$ $\mathrm{mm}^{3}$. The tests were carried out on a Thermal Instruments dynamic mechanical analyser (Q800 TA). The frequency dependent storage modulus was also evaluated with a $5-10 \mathrm{~Hz}$ frequency sweep at a constant temperature $37^{\circ} \mathrm{C}$ with $1.5 \%$ strain and $0.01 \mathrm{~N}$ static force (similar parameters were used by [32]. The storage modulus $\left(E^{\prime}\right)$ value was recorded as a function of frequency. The presented curves corresponded to the average of a three different samples.

\section{Assessment of a cellular bioactivity in simulated body fluid (SBF)}

SBF solution was prepared according to the standard procedure introduced by [33]. Specimens were immersed in $30 \mathrm{ml} \mathrm{SBF}$ in clean centrifuge tubes. There were placed inside an incubator at a controlled temperature of $37^{\circ} \mathrm{C}$ and $\mathrm{pH}$ 7.4. On the $7^{\text {th }}$ day the SBF solution was exchanged. Changes of the surface structure of immersed specimens were analysed after the specimens had been removed from SBF, washed with distilled water, and dried at ambient temperature.

\section{Structural analysis}

Incubation of scaffolds into simulated body fluids (SBF) for a few days showed that a layer containing calcium $(\mathrm{Ca})$ and phosphorus $(\mathrm{P})$ was precipitated on the surface. The surface chemistry and structure of the scaffolds surfaces after exposure to SBF were characterized using X-ray photoelectron spectroscopy (XPS) and Fourier transform infrared (FTIR) spectroscopy. XPS spectra were recorded with a Scanning Auger Microprobe - Microlab 350 (Thermo VG Scientific) spectrometer with a nonmonochromatised $\mathrm{Al} \mathrm{K}_{\alpha}(1486.6 \mathrm{eV})$ Xray source at 150 and $50 \mathrm{eV}$ pass energies.

Infrared spectra of the scaffolds surfaces were collected in a Fourier transform infrared spectrophotometer (Thermo Electron Corp. model Nicolet 6700). Measurements were carried out using the attenuated total reflectance (ATR) technique. Each sample was scanned 64 times at a resolution of $4 \mathrm{~cm}-1$ over the frequency range $400-4000 \mathrm{~cm}^{-1}$. In each case three samples were tested.

\section{Biological testing}

The human bone derived cells (HBDC) were cultured on PUR/ $\mathrm{CaCO}_{3}$ composites scaffolds to estimate their cellular biocompatibility. The cells were isolated from the trabecular bone tissue chips which were harvested from the bottom distal part of the long tight bone during a standard procedure of the knee joint alloplasty. The procedure was approved by the Local Ethics Committee of the Warsaw Medical University (Decision No. KB/ 74/2005) and the donors provided informed consent. HBDC isolation was based on the protocols described by [34] with modifications published in [35], as described in details in [36]. Cells were cultured in DMEM (Dulbecco's Modified Eagle's Medium, Gibco) supplemented with 10\% (final concentration) fetal bovine serum (FBS) (Gibco), L-glutamine (1\% solution in medium - based on $\times$ ), Gibco), stock solution 1\% antibiotic(100 -antimycotic mixture (containing 10,000 units of penicillin (base), $10 \mathrm{mg}$ of streptomycin (base), and $25 \mathrm{lg}$ of amphotericin $\mathrm{B} \mathrm{ml}^{-1}$ - (Gibco BRL, Paisley, UK), and $100 \mu \mathrm{M} \mathrm{L}$-ascorbic acid 2-phosphate (Sigma) at $37^{\circ} \mathrm{C}$ in $5 \% \mathrm{CO}_{2}$. The medium was changed every 7 days. Within $2-4$ weeks cells migrated from the bone chips. After reaching a confluence, the HBDCs were detached by means of collagenase and tripsin digestion, and used in experiments.

Prior to cell seeding, PUR/calcite scaffolds were pre-wetted under vacuum conditions in a specially designed apparatus connected to a vacuum pump. Then, samples were incubated in culture medium for $\sim 24 \mathrm{~h}$ in the standard conditions. After that, the scaffolds were transferred to the bioreactor (Spinner Basket). In the next step, $480 \mathrm{ml}$ of fresh standard culture medium mixed with the cell suspension was added (the cell number was adjusted to around $3.0 \times 10^{5}$ per scaffold [36]. The bioreactor was then transferred to the incubator $\left(37^{\circ} \mathrm{C}\right.$ in $5 \%$ $\mathrm{CO}_{2}$ ) all times keeping on the magnetic stirred (speed $\sim 60 \mathrm{rpm}$ ). The medium was changed every 7 days. In order to examine the osteogenic potential of the cells was evaluated by ALP (ALP Sigma Diagnostic Kit) activity measurements on the $7^{\text {th }}$ and $14^{\text {th }}$ day of culture. Description of the carried out biological tests is in the work [36].

\section{Results}

The results indicate the properties of $\mathrm{PUR} /$ calcite composite scaffolds for bone tissue engineering.

Figure 2 shows the SEM micrograph of the surface morphology of the composites scaffolds (PUR/calcite) immersed in SBF for 5 days. The figure clearly showed that on the surface of neat polymer scaffold was no formation of the hydroxyapatite layer. EDS analysis of its surface confirmed those results (Figure 2), which showed that the main elements were carbon and oxygen. On the other hand, examining the SEM micrographs of the surface of the calcite particles showed that it 

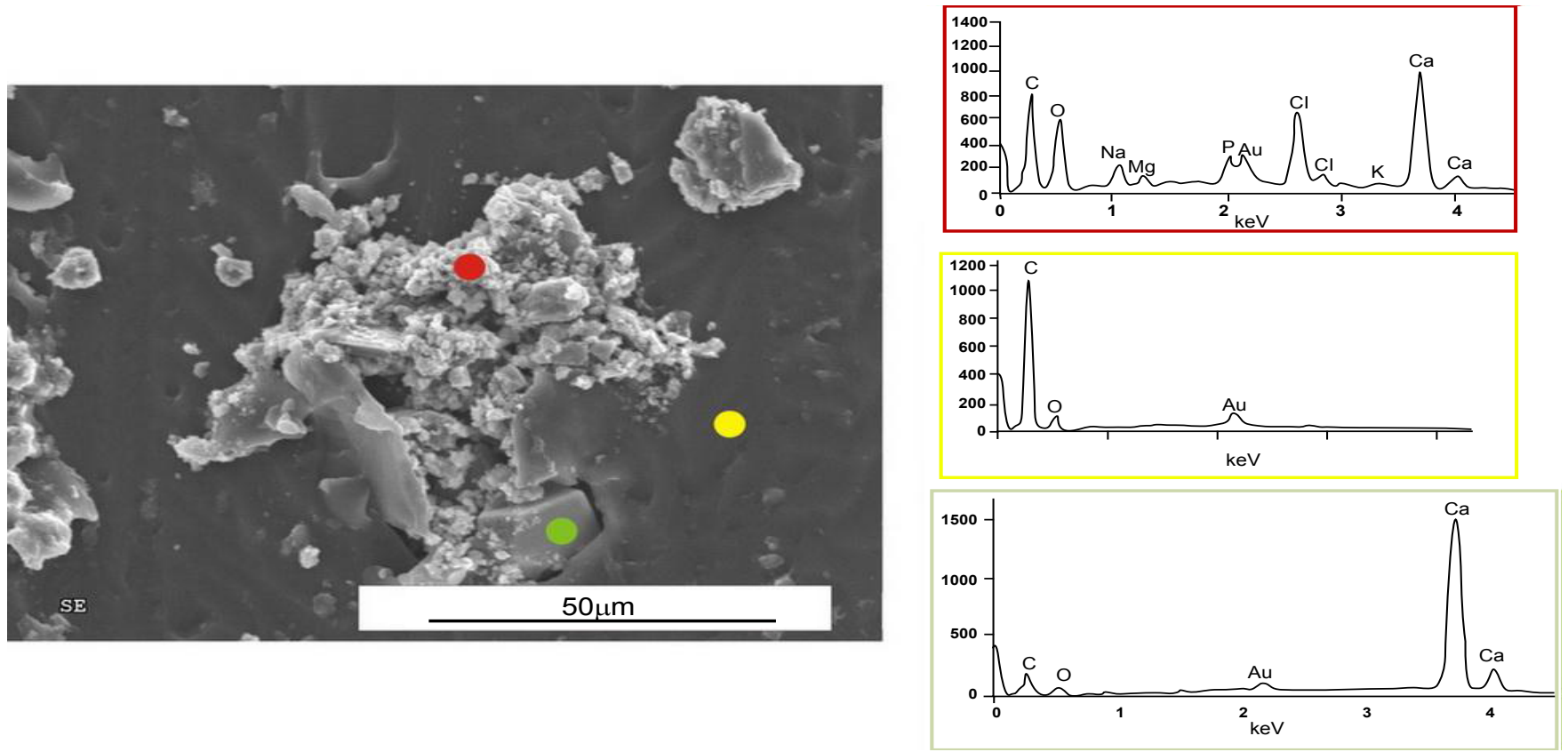

Figure 2: SEM images and EDS spectra of the PUR/calcite composites surface after immersing in SBF for 5 days.

covered with a thin layer of crystals of structure. EDS analysis (Figure 2 ) showed that the chemical composition of that layer contains mainly calcium and phosphorous.

Furthermore, the SEM micrographs of the scaffold containing calcite and immersed in SBF for 28 days, showed that it completely covered with a thick layer of a spherical crystals of porous structure (socalled 'cauliflowers' morphology) (Figure 3D). EDS analysis showed that the chemical composition of that spherical layer could be assigned to calcium-deficient and non-stoichiometric apatite. XPS analysis of its surface confirmed those results which showed that the $\mathrm{Ca} / \mathrm{P}$ ratio is equal 1.52. Comparing the SEM micrographs and EDS analyses for both neat polymer scaffolds (PUR) and the scaffolds containing calcite (PUR/calcite), showed that the apatite layer formed on the surface of $\mathrm{PUR} /$ calcite was more thick and more mineralized than that formed on the surface of PUR (Figure 3). Examination of the SEM micrographs for PUR and composite scaffolds clearly indicated that the addition of calcite to the scaffolds induced the bioactive properties to them, which could improve their bone bonding ability in vivo. The formation of the hydroxyapatite layer on the surface of composite scaffolds, could be explained by the hydrolysis of ester bonds of the polymer, and the formation of carboxylate groups $(\mathrm{COOH})$ which favors the formation of hydroxyapatite layer on the surfaces of the composite scaffolds.

The results of FTIR can be correlated with other experimental results SEM and EDS. After immersing in SBF for 14 and 28 days, the scaffolds showed many new peaks (Figure 4). In particular, the spectrum showed the characteristic absorption bands of the phosphate groups: strong band at 1021-1158 and bands at 595-599. The absorption bands of the carbonate group at 1452 and 1415 together with the weak absorption bands at 855 are characteristic of the FTIR spectra of biologically active hydroxycarbonate apatite. These bands are attributed to a partially carbonated type B hydroxyapatite considering that biological apatites are principally of type $B$.

It may be difficult to predict the effectiveness of HA chromatography based on physical and chemical properties of the desired protein to be purified. For elution, a buffer with increasing phosphate concentration is typically used. It involves nonspecific interactions between positively charged calcium ions and negatively charged phosphate ions on the stationary phase HA resin with protein negatively charged carboxyl groups and positively charged amino groups.

Micro-CT analysis clearly revealed the presence of a highly developed, quite homogenous structure and internal macroporous structure (Figure 5) but the observation with electron microscopy reveals macro- and microstructures of the obtained porous scaffolds especially for composites foams (Figure 6). Furthermore, $\mu \mathrm{CT}$ analysis was performed to quantify the variation of the microstructure of scaffolds (neat PUR and composites) before and after 28 days immersion in SBF. The results, reported in of scaffolds exhibit a high degree of open porosity (70 - 80 vol.\%). It was observed that porosity of scaffolds decreased after soaking in SBF. Moreover $\mu$ CT data analysis was used to calculate the pore size distribution. The higher size of pores for composites scaffolds we observed $\sim 230 \alpha \mathrm{m}$, pore size of PUR scaffolds was $\sim 120 \mu \mathrm{m}$. The distribution of equivalent pore diameters indicates that the pore size also decreased after soaking in SBF (Figure 7). Results from in vivo experiments showed evidently that calcite particles enhanced the formation of bone-like apatite on the surface of PUR/calcite composite scaffolds when they were immersed in SBF. The introduction of bioactivity into biodegradable scaffolds by incorporating particulate bioceramics may enhance cell-seeding and hence the subsequent tissue growth in tissue-engineered products.

Moreover, the addition of calcite particles to the polyurethanes matrix causes in changes in the mechanical properties of the scaffolds. Composites foams showed a higher storage modulus than the pure polyurethane foams (Figure 8).

The results of osteogenic potential of the cells (ALP test) completed the information about usefulness of 3D PUR/calcite composites as tissue-engineered products. The human bone-derived cells cultured in 

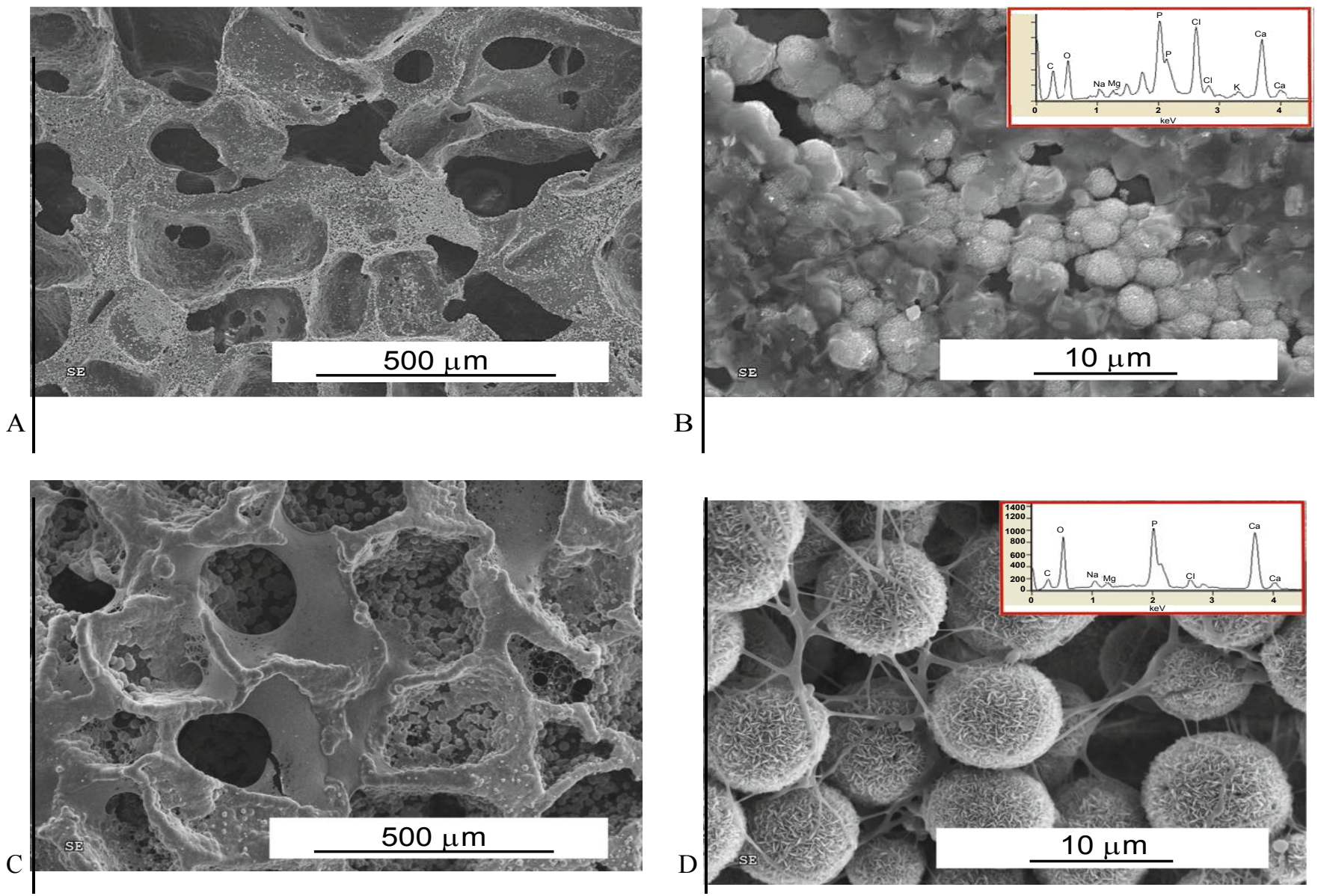

Figure 3: SEM images showing the morphology of the apatite coatings formed on the surface of porous PUR A), B) and PUR/calcite composite C), D) after immersion in SBF for 28 days.
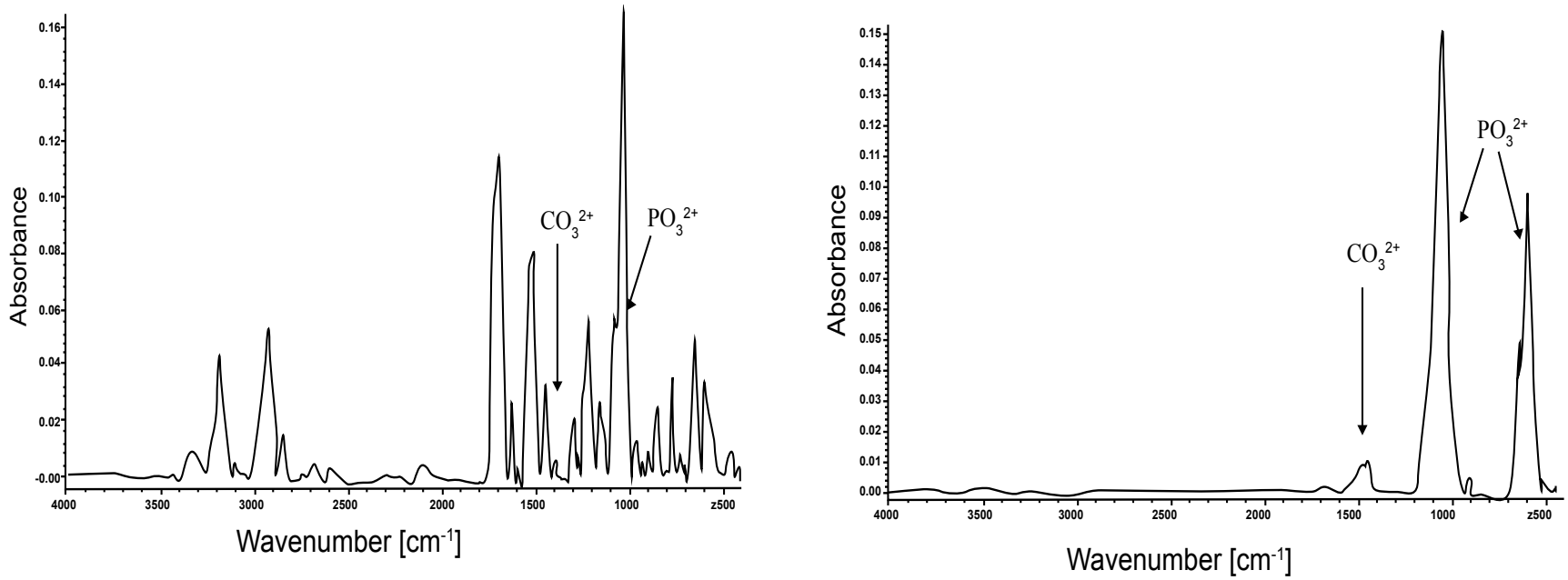

Figure 4: FTIR spectra of composites scaffolds after its immersion in SBF A) 14 days and B) 28 days.

bioreactor on the entire volume of sample showed the level of alkaline phosphatase, a characteristic marker in bone formation. The level of AP for polyurethane/calcite composite was higher as compared to PUR scaffolds after 7 days of growth but almost 2-times higher after 14 days of growth (Figure 9). The better growing properties of PUR/calcite composite could be explained by the process of calcium release to the culture medium. The larger concentration of $\mathrm{Ca}$ ions influences cellular process stimulating cells to better growth what has been observed in our previous work [19].

In order to check how cells could attach and spread on the material 
Citation: Dulinska-Molak I, Jaroszewicz J, Kurzydlowski KJ (2014) Architecture and Properties of PUR/Calcite Composite Scaffolds for Bone Tissue Engineering. J Bioprocess Biotech 4: 153 doi: 10.4172/2155-9821.1000153
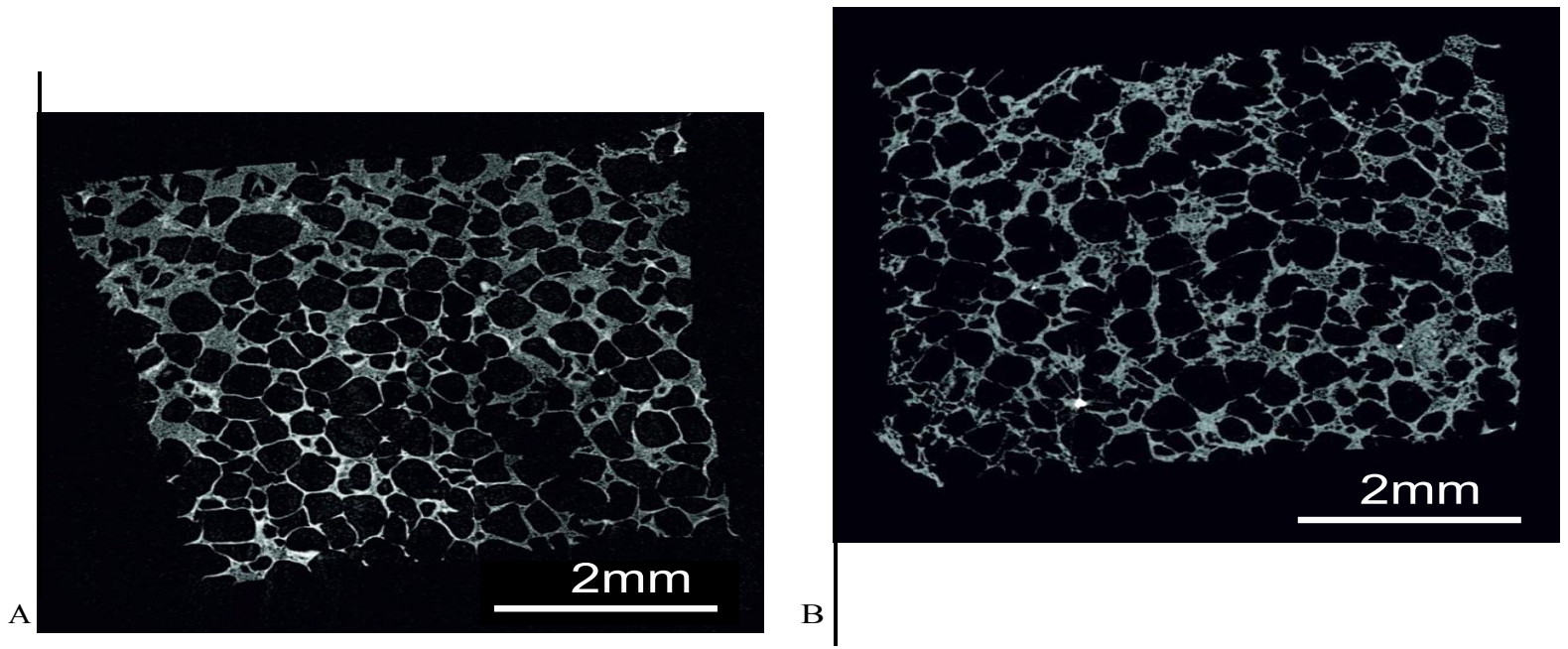

Figure 5: Representative two-dimensional $\mu \mathrm{CT}$ images showing the homogeneous pore distribution across the porous scaffolds for A) PUR and B) PUR/calcite.
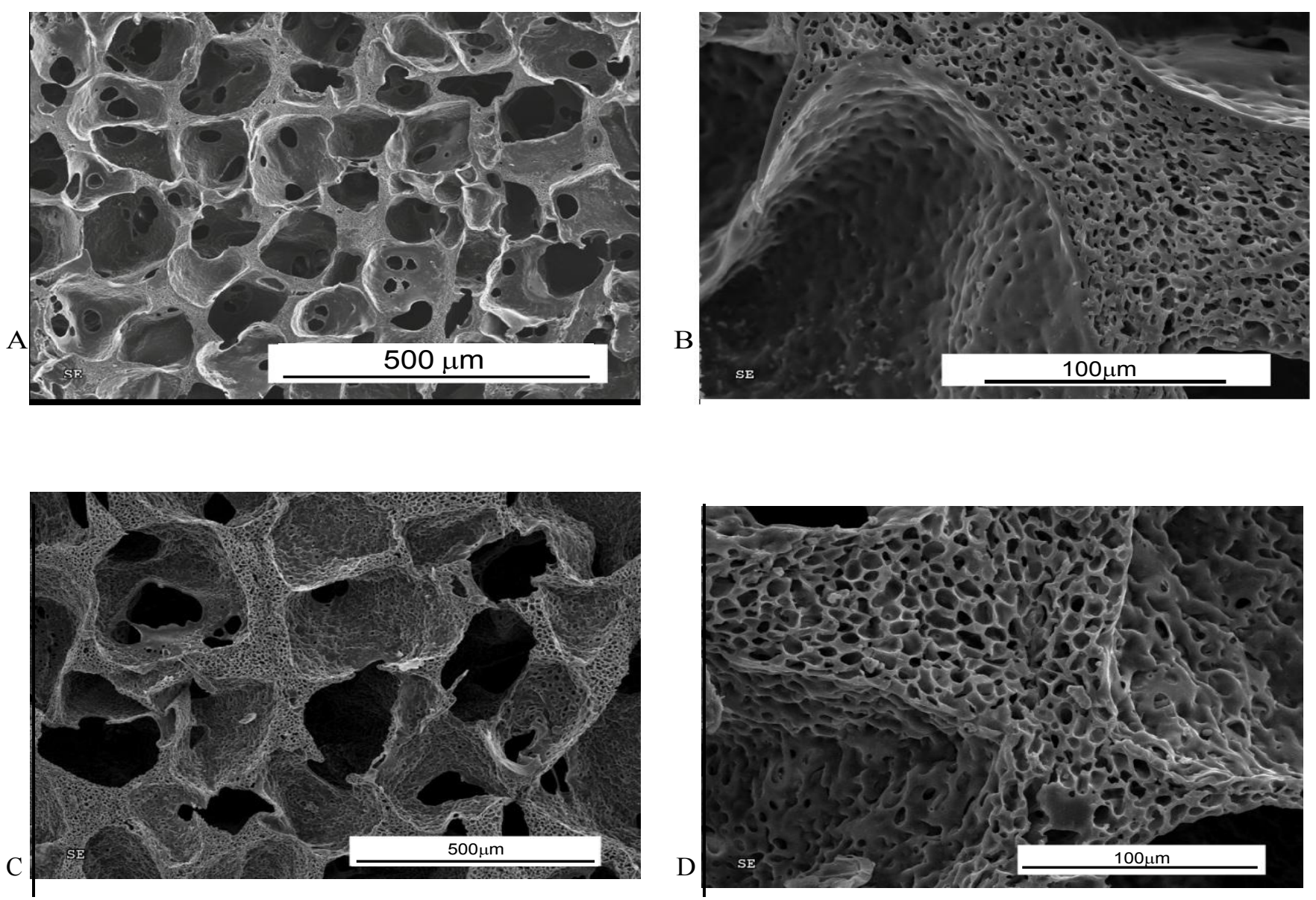

Figure 6: SEM images of porous samples of neat polyurethane A, B and of porous composite samples C, D at different magnifications.

surface observations were supplemented by electron microscopy analysis. Scaffold's crossections were examined. As seen in Figure 10 cells were located in the interior of scaffolding which shows good migration into the interior of the scaffolds. In addition, we can see that the cells adhere well to the walls of scaffolds.

\section{Conclusion}

Polymers materials used as a scaffold have insufficient mechanical and physical properties. The ceramic composites based on polyurethanes and calcite ceramics have better properties and improved applicability for implants. It is widely known that calcium carbonate particles 


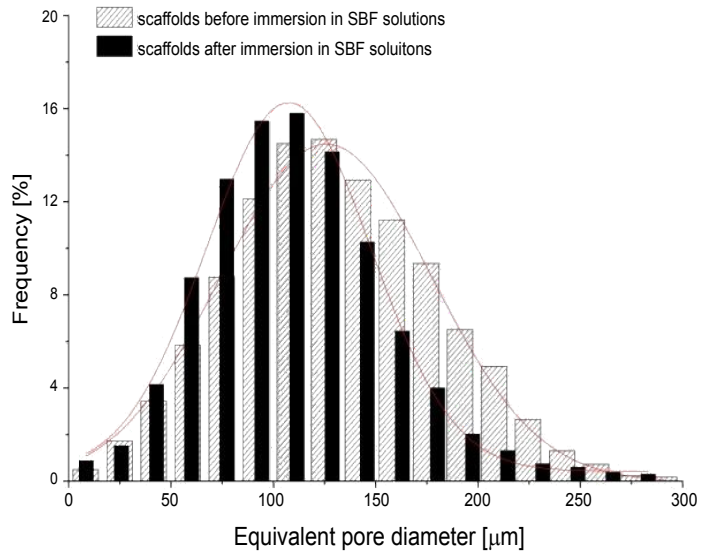

Figure 7: Frequency distribution of equivalent pore diameters in A) PUR and B) PUR/calcite scaffolds.

$\mathrm{B}$

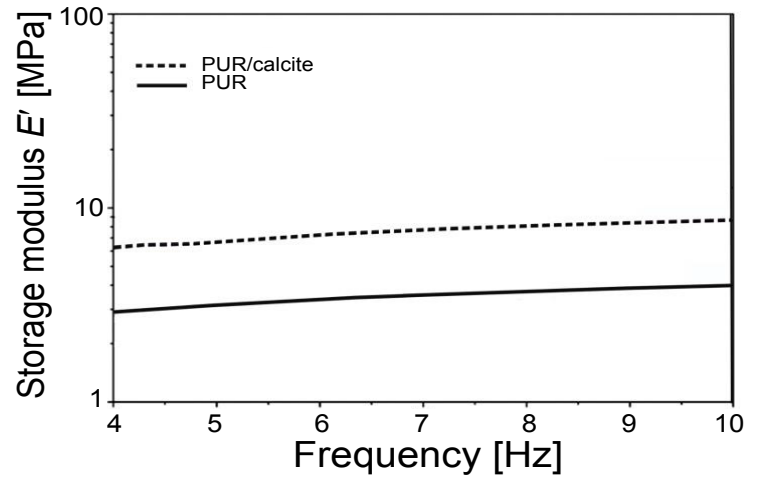

Figure 8: Variation of storage modulus $E$ ' with frequency for the porous PUR and UR/calcite scaffolds.

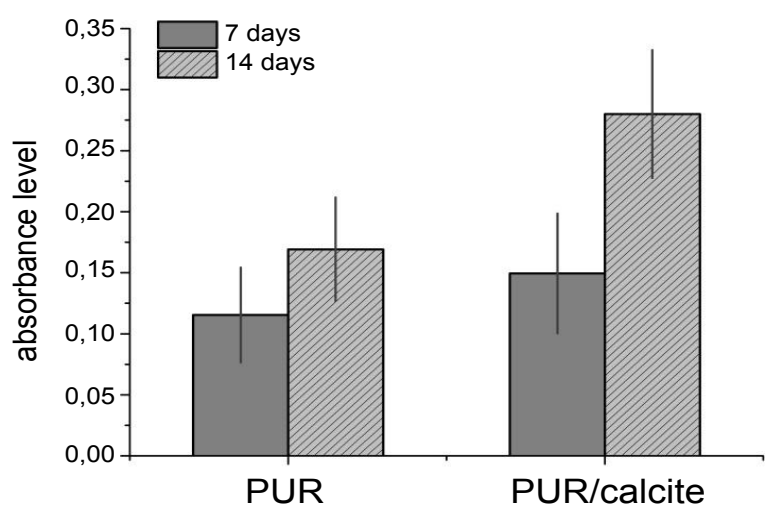

Figure 9: Alkaline phosphatase (AP) for PUR and PUR/calcite scaffolds.

also stimulate bone cells growth. The results obtained in our work confirmed that calcite particles improve the mechanical properties of composites. Furthermore we could observe a higher bio-stimulation of calcite powders. In particular, intensive nucleation of calcium phosphate on the surface of calcite filler, in comparison with PUR surface, what is responsible for bioactive properties of this material. In particular, intensive nucleation of calcium phosphate on the surface of
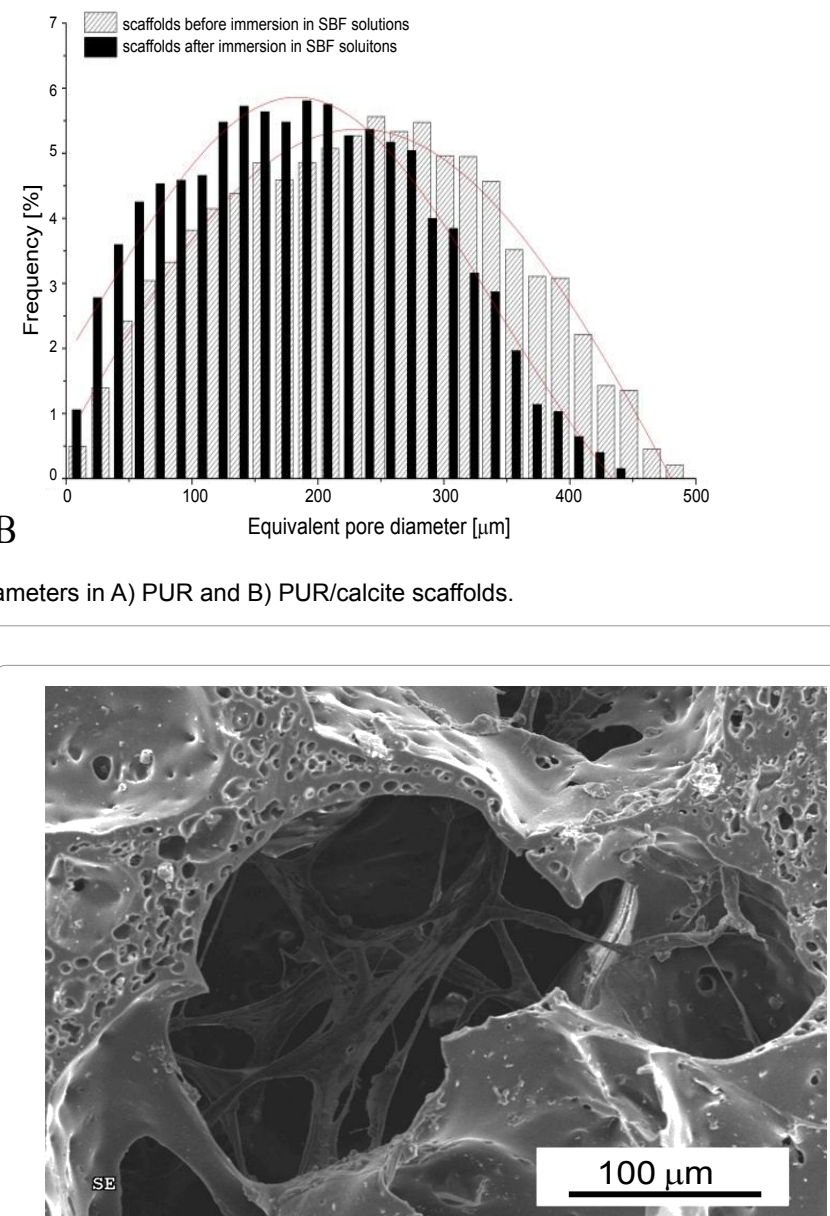

Figure 10: SEM images of cross section porous composites samples after 14 days of cultivation.

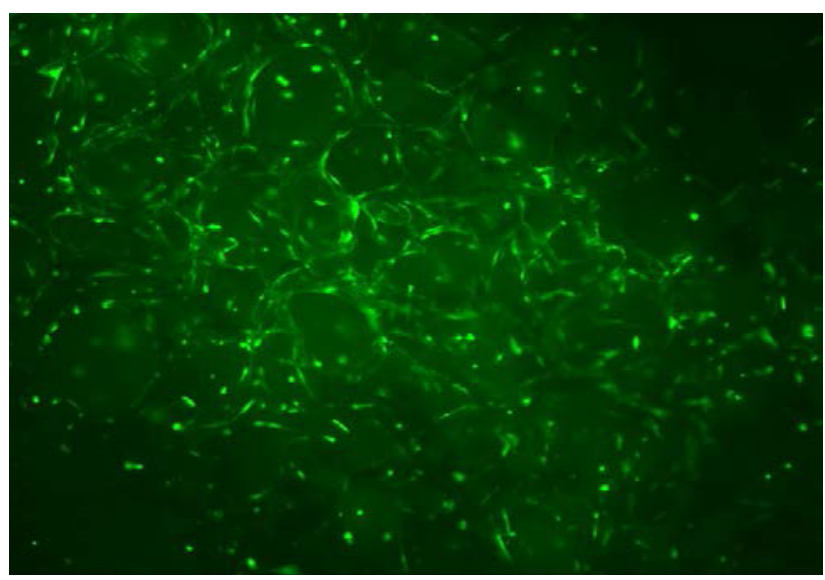

Figure 11: Cells in the pores of a scaffold in bone tissue.

calcite filler, in comparison with PUR surface, what is responsible for bioactive properties of this material. In addition, the pore architecture (macro- and micropores) and porosity exceeding 70\% satisfies the requirements for bone tissue engineering applications as fully shown in Figure 11. 
Citation: Dulinska-Molak I, Jaroszewicz J, Kurzydlowski KJ (2014) Architecture and Properties of PUR/Calcite Composite Scaffolds for Bone Tissue Engineering. J Bioprocess Biotech 4: 153 doi: 10.4172/2155-9821.1000153

Page 8 of 8

\section{Acknowledgement}

The cell culture was performed at the Warsaw Medical University by a group of Prof. Małgorzata Lewandowska-Szumieł.The synthesis of composites was Conducted in the laboratory of Dr. Joanna Ryszkowska. This work was financially supported by the grant R1301901 and Polish National Science Centre (DEC2012/07/D/ST8/02606) by the Faculty of Materials Science and Engineering, WUT.

\section{References}

1. Hutmacher DW (2000) Scaffolds in bone and cartilage. Biomaterials 21: 25292543.

2. Rezwan K, Chen QZ, Blaker JJ, Boccaccini AR (2006) Biodegradable and bioactive porous polymer/inorganic composite scaffolds for bone tissue engineering. Biomaterials 27: 3413-3431.

3. Guarino V, Causa F, Ambrosio L (2007) Bioactive scaffolds for bone and ligament tissue. Exp Rev Med Devices 4: 405-418.

4. Hutmacher DW (2001) Scaffold design and fabrication technologies for engineering tissues - state of the art and future perspectives. J Biomater Sci Polym E 12: 107-124.

5. Burg KJL, Porter S, Kellam JF (2000) Biomaterial developments for bone tissue engineering. Biomaterials 21: 2347-2359.

6. Freyman TM, Yannas IV, Gibson LJ (2001) Cellular materials as porous scaffolds for tissue engineering. Prog Mater Sci 46: 273-282.

7. Boyan BD, Hummert TW, Dean DD, Schwartz Z (1996) Role of material surfaces in regulating bone and cartilage cell response. Biomaterials 17: 137-146.

8. Lamba NMK, Woodhouse KA, Cooper SL (1997) Polyurethanes in Biomedical Applications Boca Raton, FL: CRC Press.

9. Lan PN, Corneillie S, Schacht E, Davies M, Shard A (1996) Synthesis and characterization of segmented polyurethanes based on amphiphilic polyester diols, Biomaterials 17: 2273-2280.

10. Riboldi SA, Sampaolesi M, Neuenschwander P, Cossu G, Mantero S (2005) Electrospun degradable polyesterurethane membranes: potential scaffolds for skeletal muscle tissue engineering. Biomaterials 26: 4606-4615

11. Guan J, Fujimoto KL, Sacksa MS, Wagner WR (2005) Preparation and characterization of highly porous, biodegradable polyurethane scaffolds for sof tissue applications. Biomaterials 26: 3961-3971.

12. Grad S, Kupesik L, Gorna K, Gogolewski S, Alini M (2003) The use of biodegradable polyurethane scaffolds for cartilage tissue engineering: potential and limitations. Biomaterials 24: 5163-5171.

13. Zhang J, Doll BA, Beckman EJ, Hollinger JO (2003) A biodegradable polyurethane ascorbic acid scaffold for bone tissue engineering. J Biomed Mater Res A 67: 389-400.

14. Guillemin G, Launay M, Meunier A (1993) Natural coral as a substrate for fibroblastic grown in vitro. Journal of Materials Science; Materials in Medicine 4: $575-581$.

15. Petite H, Kacem K, Triffitt JT (1996) Adhesion, grown and differentiation of human bone marrow stromal cells on non-porous calcium carbonate and plastic substrata: effects of dexamethasone and 1,25 dihydroxyvitamin D3. Journal of Materials Science; Materials in Medicine 7: 665-671.

16. Braye F, Irigaray JL, Jallot E, Oudadesse H, Weber G, et al. (1996) Resorption kinetics of osseous substitute: natural coral and svnthetic hydroxyapatite. Biomaterials 17: 1345-1350.

17. Vuola J, Goransson H, Bohling T, Asko-Seljavaara S (1996) Bone marrow induced osteogenesis in hydroxyapatite and calcium carbonate implants. Biomaterials 17: 1761-1766.

18. Ohgushi H, Okumura M, Yoshikawa T, Inoue K, Senpuku N (1992) Bone formation process in porous calcium carbonate and hydroxyapatite. J Biomed Mater Res 26: 885-895

19. Molaka ID, Lekkab M, Kurzydłowskia KJ (2013) Surface properties of polyurethane composites for biomedical applications. Applied Surface Science 270: 553-560.

20. Draghi L, Resta S, Pirozzolo MG, Tanzi MC (2005) Microspheres leaching for scaffold porosity control. J Mater Sci Mater Med 16: 1093-1097.

21. Chen G, Ushida T, Tateishi T (2002) Development of biodegradable porous scaffolds for tissue engineering. Mater Sci Eng C 17: 63-69.

22. Hou Q, Grijpma DW, Feijen J (2003) Porous polymeric structures for tissue engineering prepared by a coagulation, compression moulding and salt leaching technique. Biomaterials 24: 1937-1947.

23. Kim SS, Park MS, Jeon O, Choi CY, Kim BS (2006) Poly(lactide-co-glycolide) hydroxyapatite composite scaffolds for bone tissue engineering. Biomaterials 27: 1399-1409.

24. Monika B, Joanna R, Kurzydłowski KJ (2009) Effect of polyurethane composition and the fabrication proces on scaffold properties. J Mater Sci 44: 1469-1476.

25. Monika B, Joanna R, Piotr W, Krzysztof JK, Małgorzata LS (2010) Optimization of the structure of polyurethanes for bone tissue engineering applications. Acta Biomaterialia 6: 2501-2510.

26. Müller R (2003) Bone microarchitecture assessment: current and future trends. Osteoporos Int 14: 89-99.

27. Zeltinger J, Sherwood JK, Graham DA, Müller R, Griffith LG (2001) Effect of pore size and void fraction on cellular adhesion, proliferation and matrix deposition. Tissue Eng 7: 557-572.

28. Müller B, Beckmann F, Huser M, MasperoékelyF, GSz (2002) Non-destructive three-dimensional evaluation of a polymer sponge by micro-tomography using synchrotron radiation. Biomolecular Eng 19: 73-78.

29. Kokubo T, Kim HM, Kawashita M, Nakamura T (2000) Bone Engineering Canada.

30. Przybytniak G, Kornacka E, Ryszkowska J, Bil M, Rafalski A (2006) Influence of radiation sterilization on poly(ester urethanes) designed for medical applications. Nukleonika 51: 121-128.

31. Hildebrand T, Laib A, Muller R, Dequeker J, Ruegsegger P (1999) Direct threedimensional morphometric analysis of human cancellous bone: microstructural data from spine, femur, iliac crest, and calcaneus. J Bone Miner Res 14: 1167-1174.

32. Hafeman AE, Li B, Yoshii T, Zienkiewicz K, Davidson JM, et al. (2008) Injectable biodegradable polyurethane scaffolds with release of platelet-derived growth factor for tissue repair and regeneration. Pharm Res 25: 2387-2399.

33. Kokubo T, Kushitani H, Sakka S, Kitsugi T, Yamamuro T (1990) Solutions able to reproduce in vivo surface-structure changes in bioactive glass-ceramic A-W. J Biomed Mater Res 24: 721-734.

34. Gallagher JA, Gundle R, Beresford JN (1996) Isolation and culture of bone-forming cells (osteoblasts) from humane bone. Methods Molecular Med 2: 233-262

35. Kudelska-Mazur D, Lewandowska-Szumiel M, Mazur M, Komender J (2005) Osteogenic cell contact with biomaterials influences phenotype expression. Cell Tissue Bank 6: 55-64.

36. Woźniak P, Bil M, Ryszkows J, Wrobel E, Ratajska A, et al. (2010) Candidate bone-tissue engineered product based on human-bone-derived cells and polyurethane scaffold. Acta Biomaterialia 6: 2484-2493. 